\title{
MENELUSURI JEJAK ISLAMISASI DI TATAR SUNDA MELALUI NASKAH KUNO
}

\author{
Yuyun Juariah
}

\begin{abstract}
Abstrak
Kajian mengenai sejarah islamisasi tatar Sunda menarik untuk terus digali dari sumber aslinya langsung yaitu naskah kuno yang merupakan warisan kekayaan intelektual masa lalu. Sudah selayaknya kita mau membuka diri terhadap informasi yang berasal dari kearifan local masyarakat tatar Sunda. Museum Sri Baduga menyimpan banyak manuskrif kuno yang membahas islamisasi di tatar sunda dan sampai saat ini masih sedikit para akademisi serta peneliti yang mempergunakan hasil transliterasi yang dilakukan para ahli filologi.Dalam kaitannya dengan proses islamisasi yang termuat dari teks naskah Babad Banten (BB) diperoleh kesimpulan sebagai berikut : Pertama ; islamisasi tidah hanya dilakukan melalui jalur politik dengan mengatasnamakan kekuasaan atau kewenangan sultan semata. Kedua, islamisasi tidak pernah dilakukan melalui jalur kekerasan atau perang tanpa alasan yang jelas. Penyerangan atau ekspansi kekuasaan lebih disebabkan oleh factor politik dengan motif perebutan kekuasaan. Ketiga, islamisasi yang memberikan dampak besar melalui pendekatan budaya atau tradisi karena semua lapisan masyarakat terlibat langsung secara emosi. Keempat, proses islamisasi sendiri tidak akan terjadi tanpa adanya kesiapan yang kuat dari para penyiar agama itu sendiri. Kesungguhan sultan mendidik putranya dalam ilmu agama merupakan bukti betapa hal ini menjadi satu keharusan untuk menyiapkan diri penerus syiar Islam di masa yang akan datang.
\end{abstract}

\section{A. Pendahuluan}

Kapan dimulainya proses islamisasi di Indonesia, hingga saat ini masih diperdebatkan waktu kepastiannya. Beberapa sejarawan menyebutkan abad ke 7, sebagian lainnya menyebutkan abad ke 13. Para ahli yang menyebutkan Islam masuk ke Indonesia pada abad ke 7 didukung oleh berita dari Cina zaman Dinasti Tang, yang menjelaskan bahwa pada tahun 674 Masehi ditemukannya perkampungan orang-orang Arab yang beragama Islam di pantai barat Sumatera dengan nama perkampungan Barus atau fansur.
Para ahli yang menyebutkan bahwa penyebaran Islam dilakukan pada abad ke 13 didukung oleh bukti sebagai berikut; pertama, catatan perjalanan Marco Polo yang menerangkan bahwa dirinya pernah singgah di Perlak pada tahun 1292 dan bertemu dengan orang-orang yang beragama Islam. Kedua, ditmukannya nisan makam Raja Samudera Pasai, Sultan Malik As Saleh yang berangka tahun 1297 Masehi. Berdasarkan beberapa pendapat para ahli sejarawan tersebut, maka para ahli sejarah cenderung menyimpulkan bahwa masuknya Islam ke Indonesia terjadi 
pada abad ke tujuh sedangkan abad ke 13 menunjukan adanya perkembangan Islam hingga munculnya kerajaan-kerajaan Islam di Indonesia. (Anwar dan Suryana, 2006:70)

Sementara itu, sumber sejarah menyebutkan bahwa Islam mulai berkembang di Pulau Jawa pada abad ke 11, dengan bukti ditemukannya batu nisan Fatimah binti Maimun di Leran, Gresik yang berangka tahun 1082 Masehi. Pertumbuhan masyarakat muslim di Pulau Jawa sendiri terus meningkat saat munculnya kerajaan Demak yang di pimpin oleh Raden Patah sekitar tahun 1500.

Bagaimana dengan penyebaran agama Islam di Tatar Sunda? Untuk menjawab pertanyaan ini, maka kita harus melakukan kajian naskah Babad Banten (BB) ditulis pada tahun 1662/63 Masehi oleh penulis yang menamakan dirinya Sandimaya ${ }^{1}$ dan Sandisastra ${ }^{2}$. Naskah Babad Banten (BB) menjadi penting untuk dikaji karena BB menjelaskan bagaimana kondisi masa lalu Banten hingga masa Pangeran Adipati atau lebih dikenal dengan sebutan Sultan Agung II yang bergelar Sultan Abul Fath Abdul Fatah. BB juga menginformasikan proses islamisasi yang dilakukan oleh Sunan Gunung Djati dan Maulana Hasanuddin kepada penguasa Banten Girang beserta penduduknya.

Heryana (2015: 3) menyebutkan, setidaknya ada tiga alasan mengapa teks Babad Banten (BB) menarik untuk dikaji lebih dalam,

\footnotetext{
${ }^{1}$ Sandimaya adalah orang yang menuturkan cerita Babad Banten

${ }^{2}$ Sandisastra adalah orang yang menuliskan cerita yang diceritakan oleh Sandimaya kepada dirinya.
}

karena ; Pertama, Banten pada masa pra Islam berada dibawah kekuasaan Kerajaan Pajajaran dimana pada saat itu Pajajaran sedang dalam kondisi kehilangan kewibawaannya sehingga banyak kerajaan yang ada di bawah kekuasaannya membangkah dan berusaha memisahkan diri. Kedua, Penyebaran Islam terkesan dilakukan melalui kekuatan militer dengan seringnya terjadi penaklukan terhadap kerajaan lainnya, sementara dalam ajaran Islam peperangan harus dihindari dan Islam disebarkan dengan cinta bukan dengan pedang. Ketiga, bagaimana proses Islamisasi di wilayah Banten sehingga generasi berikutnya dapat terinspirasi atas seluruh proses islamisasi tersebut.

Naskah BB bukanlah naskah tunggal, melainkan ada puluhan salinan dengan sebutan yang berbeda. Naskah BB koleksi No 07.74 Museum Sri Baduga yang menjadi sumber penelaahan ini bukanlah teks naskah lengkap. Guna memberikan gambaran utuh atas jalan ceritanya, maka ketika melakukan literasi, Heryana membandingkannya dengan teks Sajarah Banten karangan Djajadiningrat (1983).

\section{B. Pembahasan}

Salahsatu kekayaan budaya masyarakat Jawa Barat yang sangat berharga adalah naskah kuno ${ }^{3}$. Naskah kuno berisi rekaman berbagai informasi tentang banyak hal, diantaranya sejarah, silsilah, adat istiadat, agama, pertanian, pengobatan, penanggalan, ilmu

\footnotetext{
3 Naskah kuno merupakan karya tertulis produk masa lampau dalam bentuk aksaraaksara tertentu didalamnya memiliki arti dan makna penting bagi sosial kebudayaan sebuah masyarakat pada masanya.
} 
pengetahuan, kesusastraan dan lainnya. Isi naskah kuno ini kemudian ditransliterasi (alih aksara dan alih bahasa) kedalam aksara latin dan bahasa Indonesia oleh para ahli filologi. Menurut Aries (2015), hingga tahun 2014 ada 156 buah naskah kono yang ditulis dalam aksara dan bahasa kuno yang tidak dipahami kecuali oleh para ahli filologi. Sampai tahun 2015, para ahli filologi museum Negeri Sri Baduga telah berhasil menstransliterasi 110 judul naskah. Hasil transliterasi ini kemudian diinformasikan kepada masyarakat melalui seminar dan penerbitan prosiding makalah. Museum Negeri Sri Baduga juga menyajikan tradisi tulis masyarakat masa lalu yang dituangkan dalam bentuk naskah, prasasti maupun piagam, tetapi juga dalam bentuk benda pakai, alat tukar (mata uang), golok, keris, pedang dan benda seni lainnya. Media teknis yang digunakan untuk menulis sangat beragam, yaitu pada kain (melalui teknik batik), kayu, bambo (seperti ukiran pada kolenjer), tulisan pada nisan, kaca, senjata, kanvas, benda keramik, jimat dan lain sebagainya. Teks naskah yang dipamerkan Museum Negeri Sri Badunga seperti ; (1) naskah Siksa Kandang Karesian (1518Masehi). (2) naskah Nitistuti (15 Masehi), (3) Sanghyang Raga Dewata (16 Masehi), (4) naskah kaagamaan, (5) naskah riwayat Nabi Muhammad, (6) Serat Banyu Urip, (7) naskah khotbah, (8) naskah kitab doa, (9) kitab tauhid dan fiqih, (10) serat Darmawulan, (11) palilindon, (12) Lontar Sutasoma. Isi dari teks-teks naskah ini merupakan pedoman (ageman), etika, ajaran keagamaan dan budi pekerti.
Dari 110 judul naskah kuno yang telah berhasil di transliterasi museum, penulis tertarik untuk mengkaji lebih jauh hasil transliterasi yang berhubungan dengan proses penyebaran agama Islam di tatar Sunda, mengingat proses masuknya agama Islam ke Indonesia hingga saat ini masih diperdebatkan waktu kepastiannya, maka penulis merasa perlu mengkaji BB untuk melihat bagaimana proses islamisasi dari sumber yang berkembang di masyarakat saat itu. Menurut Sariah (2016) naskah kuno yang baik adalah naskah yang banyak ditulis ulang oleh beberapa penulis dari berbagai kalangan. Penulis dari kalangan rakyat jelata biasanya lebih objektif menuturkan apa yang mereka lihat dan rasakan sehingga kebenarannya dapat lebih diakui. naskah Babad Banten (BB) ditulis pada tahun 1662/63 Masehi oleh penulis yang menamakan dirinya Sandimaya dan Sandisastra. (Djajadiningrat, 1983:8) BB menjelaskan bagaimana kondisi masa lalu Banten hingga masa Pangeran Adipati atau lebih dikenal dengan sebutan Sultan Agung II yang bergelar Sultan Abul Fath Abdul Fatah. (Heryana, 2015:3)

Naskah kelompok babad memiliki kandungan informasi yang sangat penting sebagai sumber sejarah maupun pengetahuan lain yang berhubungan dengan kondisi sosial budaya pada wilayah tertentu seperti yang tercantum pada konteks ceritanya (Heryana, 2015:3). Untuk mempelajari lebih jauh mengenai proses masuknya Islam ke Tatar Sunda, maka kedudukan naskah kelompok babad ini menjadi sangat penting untuk di pelajari lebih jauh. Dengan demikian, apabila kita akan memperlajari sejarah proses masuknya islam di tatar Sunda, 
maka kita harus mempelajari hal tersebut dengan mengacu kepada kaidah-kaidah sejarah. Kuntowijoyo (2003: 157-160) menjelaskan bahwa sejarah memiliki tiga kaidah, yaitu; (1) sejarah berisi fakta (2) bersifat diakronis, melihat segala sesuatu dari sudut rentang waktu, sehingga melihat perubahan, kesinambungan, ketertinggalan dan loncatannya), ideografis artinya melukiskan (menggambarkan, memaparkan, menceritakan) dan unik (karena mencari yang sifatnya khas dan berlaku pada sesuatu, disitu dan waktu itu), (3) empiris karena bersandar pada pengalaman manusia yang sungguh-sungguh. Akan tetapi, Kuntowijoyo juga menyebutkan bahwa untuk kronik, hikayat, syair dan babad yang kebanyakan ditulis jauh sesudah kejadian, harus diterapkan prosedur standar dari ktitik sejarah.

\section{Naskah Babad Banten}

Naskah Babad Banten atau disebut juga Sajarah Banten merupakan naskah yang banyak diminati masyarakat luas pada masanya dan menadi acuan dalam menggali lebih jauh sejarah masalalu Banten. Ciri sebuah naskah popular dan diminati pembaca adalah banyaknya naskah salinan. Pada masa lalu, penggandaan naskah dilakukan dengan cara menyalin sehingga apabila seseorang ingin memiliki naskah Babad Banten, maka ia harus menyalinnya atau menyuruh seseorang dengan bayaran tertentu.

Naskah Babad Banten
bukanlah naskah tunggal.
Berdasarkan pemeriksaan atas
berbagai katalog naskah yang
dilakukan Heryana dan informasi
Hoesein Djajadiningrat (1983)
diketahui bahwa naskah-naskah yang

berjudul Sajarah Banten berjumlah 28 buah dan dua diantaranya hilang. Jumlah diatas bukan angka yang mutlak, karena bisa saja ditemukan lagi naskah sejenis seperti Babad Banten yang telah dialihaksarakan dan dialihbahasakan oleh Zahrotul Mahmudah dan Tri Kurnia Dewi pada tahun 2011. (Heryana, 2015:6)

Teks Babad Banten secara garis besar merupakan sejarah kesultanan Banten yang dimulai dari pemerintahan : (1) Molana Hasanudin, (2) Molana Yusuf, (3) Molana Muhammad atau Kangjeng Ratu Banten Surasowan atau Prabu Seda ing Palembang, (4) Pangeran Abdullah Kadir dengan gelar Pangeran Ratu. Beliau mendapat gelar dari Sultan Mekah sehingga gelarnya menjadi Seltan Abdulmafikhir Mahmud Abdulkadir atau lebih dikenal dengan sebutan Sultan Agung I, dan (5) Sultan Abul Fath Abdul Fatah.

Djajadiningrat (1983:145-155) menyebutkan, penyebaran agama Islam di Banten dilakukan secara intensif sejak masa pemerintahan Hasanuddin (1526-1570) di daerah pesisir dan pedalaman. Upaya memperkenalkan agama Islam ke daerah Bogor yang pada saat itu merupakan pusat kerajaan Sunda dilakukan oleh Molana Yusuf, putra Hasanuddin pada tahun 1579 Masehi. Beliau pula yang memimpin pasukan Islam untuk menduduki ibukota pakuan Pajajaran.

\section{Ringkasan Isi Sajarah Banten}

Dalam Lor.7389 teks Sajarah Banten dibagi dalam dua bagian. Bagian pertama berisi cerita-cerita kerajaan masa lalu, yaitu sejarah Jawa dari masa sebelum Islam sampai pengislaman Tanah Jawa (pupuh 1-16) dan bagian kedua 
berisi kisah pengislaman dan pendirian kerajaan Banten oleh Maulana Hasanuddin ampai masa pemerintahan Sultan Abul Fath Abdul Fatah atau Sultan Agung Tirtayasa (pupuh 17-66) (Pudjiastuti, 2007)

Berikut dikemukakan ringkasan Sajarah Banten yang berkaitan dengan islamisasi atau proses pengislaman Banten (Pudjiastuti, 2007: 250-261)

\section{Pupuh 1-2 Sandimaya menasehati dan mengajarkan sifat-sifat raja yang baik dan kewajiban yang harus dijalankan seseorang abdi kerajaan.}

Pupuh 3 Silsilah Sunan Gunung Jati yang menurunkan raja-raja Banten dalam garis naik sampai kepada Nabi Muhammad SAW. Dikisahkan pula Raden Galuh dari kerajaan Medang Kamolan, ayah Raden Tanduran (pendiri Majapahit).

Pupuh $4 \quad$ Cerita asal-usul Ciung Wanara (pendiri Padjajaran) yang juga putra Raden Galuh, Raja Medang Kamolan.

Pupuh 5 Kisah tentang Gajahmada dan Ki Dilan (Arya Damar).

Pupuh 6 Kisah tentang kelahiran Bondhan Kejawan.

Pupuh 7 Bondhan Kejawan tahu rahasia dirinya. Ia adalah putra Raja Majapahit dari selir.

Pupuh 8 Kisah anak-anak Bondhan Kejawan: Pamanahan dan Panjuwed.
Pupuh 9 Relasi Majapahit dengan Cempa melalui perkawinan raja Majapahit dengan putri Cempa.

Pupuh 10 Perkawinan raja Majapahit dengan putri Cina.
Dalam keadaan hamil diserahkan kepada putranya, Arya Damar yang diberi kekuasaan sebagai penguasa di Palembang. Dikisahkan juga pertemuan Raden Sahid, putra Tumenggung Wilatikta dengan Sunan Bonang.

Pupuh 11 Raden Sahid menjadi murid Sunan Bonang. Kelak ia dikenal sebagai Sunan Kali Jaga.

Pupuh 12 Kisah She Samsu Tabras, putra Jumadilkubra dari hubungan inses dengan putrinya sendiri.

Pupuh 13 Kisah Pangeran Makdum (Sunan Gunungjati), murid Molana Ulul Islam uang menjadi raja di Cirebon. Ia mempunyai dua orang anak, yang perempuan dijadikan raja di Cirebon (Pakungwati) dan yang laki-laki di Banten.

Pupuh 14 Asul-usul Jaka Tingkir.

Pupuh 15 Jaka Tingkir menikah dengan putri Sultan Demak dan diberi gelar Pangeran Dipati. Wilayah kekuasaannya Pajang.

Pupuh 16 Kisah Molana Hasanudin. Ia adalah putra wali dari Cirebon. Molana diperintahkan ayahnya untuk menaklukkan Pucuk Umun, penguasa Banten Girang.

Pupuh 17 Molana Hasanudin diajak ayahnya ke Mekah. Sekembalinya dari Mekah, ia mengislamkan Banten.

Pupuh 18 Molana Hasanudin dinikahkan dengan putri Sultan Demak, bernama Pangeran Ratu. Molana Hasanudin dinobatkan sebagai Raja Banten. Ia juga mengislamkan Lampung, Indrapura, Sulebar, dan Bengkulu. 
Pupuh 19 Sunan Gunungjati

Banten Surasowan. Pada masa memberi petunjuk kepada Molana Hasanudin untuk membangun kota pantai, pasar, dan alun-alun di Banten. Pakwan Pajajaran ditaklukkan.

Pupuh $20 \quad$ Parungsiaji ditaklukkan. Sunan Gunungjati membagi Karawang menjadi dua bagian. Sebelah Timur masuk wilayah Cirebon dan sebelah Barat wilayah Banten.

Pupuh 21 Aktivitas Molana Hasanudin di istana. Pagi dan petang bertugas sebagai raja dan malam bertapa.

Pupuh 22 Molana Hasanudin wafat pada usia 100 tahun. Ia digantikan putranya bernama Molana Yusuf. Raja baru memperluas pembangunan kota Banten dengan membuat benteng, kampong, sawahladang, terusan, dan bendungan. Molana Yusuf wafat dalam usia 80 tahun dan digantikan oleh putranya, Molana Muhammad yang membangun Banten dari segi agama.

Pupuh 23 Sandisastra meminta kepada Sandimaya menceritakan kisah Molana Muhammad saat menyerang Palembang.

Pupuh 24 Saat Molana Yusuf sakit, ia berpesan: jika dirinya wafat, maka putranya, Molana Muhammad, walaupun masih kecil harus diangkat sebagai raja. Mangkubumi menjadi walinya sampai tiba saatnya Molana Muhammad mampu mengemban tugas sebagai raja Banten. Ketika Molana Yusuf wafat, Molana Muhammad diangkat sebagai raja Banten dengan gelar Kanjeng Ratu itu, kapal Parenggi tiba di Banten.

Pupuh 25 Pangeran Mas dari Demak datang ke Banten mengajak Molana Muhammad menyerang Palembang yang masih kafir. Molana Muhammad menyetujuinya. Dalam peperangan itu, Molana Muhammad gugur. Jenazahnya dibawa pulang ke Banten. Saat Molana Muhammad berangkat perang, permaisurinya, Nayi Gedhe Wanogiri sedang hamil tua. Jenazah Molana Muhammad tiba Banten, ketika permaisuri baru saja melahirkan. Oleh karena itu, putra Molana Muhammad yang masih bayi diberi nama Pangeran Abdullah Kadir dinobatkan sebagai raja Banten di depan jenazah ayahnya dengan perwakilan Mangkubumi. Molana Muhammad diberi gelar Prabu Seda ing Palembang.

Pupuh 26 Pangeran Abdullah Kadir diangkat sebagai raja Banten ketika masih bayi dengan gelar Pangeran Ratu. Tugas pemerintahan diurus pleh Mangkubumi dengan perwakilan ibunya, Nyai Gedhe Wanogiri. Mangkubumi tua wafat. Para menteri dan bangsawan Banten mengangkat Mangkubumi baru dan menikahkannya dengan Nyai Gedhe Wanogiri. Mangkubumi bari sangat sayang kepada Pangeran Ratu, demikian pula sebaliknya, sehingga orang menghormatinya seperti kepada raja. Hal ini menimbulkan kecemburuan bangsawan Banten. Akhirnya 
para bangsawan itu di bawah pimpinan Pangeran Upapatih dan Pangeran Ranamanggala bersepakat melenyapkan Mangkubumi baru. Dipati Yudanegara ditugaskan membunuhnya. Namun, setelah berhasil melaksanakan tugas, ia malah dikejar dan dituduh pemberontak. Merasa disudutkan, Yudanegara lari ke hilir sungai dan bergabung dengan Pangeran Kulon. Ia menghasut Pangeran Kulon agar menuntut tahta Banten. Pangeran Upapatih dan Pangeran Ranamanggala membawa pasukan untuk menumpas pemberontakan Pailir.

Pupuh 27 Yudanegara dan Pangeran Kulon berperang melawan pasukan Banten yang menyerbu Pailir.

Pupuh 28 Pasukan Banten dibawah pimpinan Pangeran Upapatih menyerbu para pemberontak di Pailir, sedangkan Pangeran Ranamanggala dan Raja Banten Pangeran Abdullah Kadir yang masih kecil menyaksikan peperangan itu. Peperangan usai saat Pangeran Jaketra menengahinya. Ia membawa pemberontak ke Jaketra. Setelah empat tahun berada di Jaketra, para pemberontak kembali ke Banten.

Pupuh 29 Dipati Sumenep datang ke Banten meminta perlindungan karena diserbu Mataram. Banten tidak mau berurusan dengan Mataram. Mereka dikembalikan lagi ke Sumenep. Setelah itu, Pangeran Padjajaran datang ke
Banten dengan alasan yang sama. Namun karena masih berkerabat, ia diizinkan dan diberi tempat tinggal di daerah Pontang. Dikisahkan kapal Belanda merapat di Angke dipimpin Kapiten Jangkung (Jan Pietersszoon Coen). Ia meminta izin kepada Pangeran Jaketra untuk menyewa tanah dan membuat gudang. Permintaannya dikabulkan. Ia datang meminta izin lagi membangun pagar tinggi dengan alasan barang-barang yang dijemur di halaman rumah nya selalu dicuri. Selang beberapa waktu, kapal besar Belanda merapat di Jaketra tetapi karam. Kapiten Jangkung meminta izin mengangkuti barangbarangnya ke tempatnya. Pangeran Jaketra mengizinkannya. Namun, Kapiten Jangkung tidak jujur. Siang hari, barang yang diangkut adalah barang biasa, tetapi malam hari, adalah senjata.

Pupuh $30 \quad$ Kapiten Jangkung pergi ke Surasowan untuk mendapat pengesahan atas kedudukannya di Jakerta. Ia menyatakan kesediaannya membantu Banten jika suatu saat mendapat serangan dari Timur. Pangeran Ranamanggala setuju. Kebanyakan bangsawan Banten menentangnya. Mereka berpendapat orang belanda akan jadi racun kelak, sebaiknya dibasmi saja. Tapi, pangeran ranamanggala beranggapan orang belanda dapat dimanfaatkan sebagai 
dinding pemisah antara banten dan mataram.

Pupuh 31 Kapiten Jangkung memancing kerusuhan dengan menembaki keraton pangeran Jaketra. Terjadi peperangan. Pangeran Ranamanggala mengurus pangeran Upapatih, pangeran Madura, dan pangeran Sabrang Lor untuk menjemput pangeran Jaketra ke Banten. Awalnya, pangeran jakerta menolak, tatapi akhirnya ia bersedia. Ia diberi tempat di jampalahon. Belanda membangun benteng dan menempatkan meriam di 4 arah mata angin. Jatuhnya jakerta diberi sengkala tanpa warna tata iku (=1450 saka).

Pupuh 32 Permaisuri Pangeran Patu atau pangeran abddulah kadir adalah putri pangeran rangga singasari. Dari permaisuri pangeran ratu mempunya 5 orang anak, satu diantaranya adalah pangeran pekik yang dirawat dan di asuh Pangeran Ranamanggala. Pangeran Pekik dinikahkan dengan putri Pangeran Jaketra dalam sebuah pesta besar yang dihadiri oleh orang cina, keling, Inggris, dan Belanda.

Pupuh 33 Mataram menyerbu Belanda di Jaketra, pasukannya dipimpin Bahureksa. Sulttan Banten mengirimkan pasukannya ke Tanggerang dibawah pimpinan Tumenggung Wirautama untuk berjaga-jaga diperbatasan. Ekspedisi Mataram ini gagal. Belanda berhasil mengusir penyerbunya.

Pupuh 34 Mataram mengirim ekspedisi kedua dibawah pimpinan Tumenggung
Singaranu. Penyerbuan ini juga gagal. Orang Banten memancing peperangan dengan Belanda dengan melakukan tindakan pencurian dan perampokkan. Orang-orang Jaketra, Bali, Kolasi dan Wandan diculik dan dijual ke Lampung. Belanda kewalahan dan mengusulkan permainan peperangan. Raja Banten dan para punggawa menyambut gembira usul itu. Ketika itu, pangeran ranamanggala telah wafat.

\section{Pupuh $35 \quad$ Permainan}

peperangan dilaksanakan, tetapi yang boleh bermain hanya rakyat kecil dan Belanda harus selalu kalah. Orang Banten mengusulkan peperangan dengan kapal besar bernama Barungut yang rusak harus diperbaiki dulu di Batawi. Selesai diperbaiki, Wangsadipa mengusulkan agar kapal dibakar. Malam harinya kapal Barungut dibakar. Peristiwa terbakarnya kapal Barungut disebut Pabaranang. Orang Belanda kewalahan menghadapi Banten akhirnya mengusulkan perdamaian.

Pupuh $36 \quad$ Susuhunan Mataram marah kepada Dipatiukur karena tidak mau ikut menyerang Jaketra. Dipatiukur melarikan diri ke gunung Panaekan. Ia mengirim menantunya, Demang Tisna Jaya dan cucunya, Mas Wangsaraja ke Banten untuk meminta bantuan. Kebetulan pada waktu itu, Raja Banten, Pangeran Abdullah Kadir mengirim utusan ke Mekah.

Pupuh 37 Atas usul
Wangsadipa, Pangeran 
Abdulah Kadir mengutus Demang Sacawacana ke Ukur. Demang Tisnajaya dan Mas Wangsaraja diutus ke Mekah dengan membawa 3 buku, yaitu markum, mumtahi dan wujudiah serta hadiah pala, cengkeh, dan kasturi untuk sultan Mekah.

Pupuh 38 Sacawacana tiba di Ukur, tetapi tatkala Dipatiukur telah dikepung pasukan Mataran dan tidak bisa diselamatkan lagi, ia kembali ke Banten. Pangeran Abdulah Kadir tidak marah atas keputusannya, bahkan atas jeripayah nya, ia diberi hadiah. Utusan Banten tiba di Judah (Jeddah) Mekah. Mereka dibawa menghadap Sultan Mekah, Sultan Syarif Jahed.

Pupuh 39 Utusan Banten diterima Sultan Mekah. Hadiah Sultan Banten diterima dan dibagikan kepada bangsawan. Sebagai balasan, Sultan Mekah memberi hadiah berupa bendera nabi Ibrahim, tirai penutup makan nabi Muhammad, dan kiswah penutup ka'bah serta arti ketiga kitab yang ditanyakan sultan banten. Selain itu, Sultan Mekah memberi gelar Sultan kepada raja banten dan anaknya. Raja Banten, pangeran abdulah kadir menjadi Sultan Abul Mafakhir Mahmud Abdul Kadir, dan anaknya, pangeran Pekik menjadi Sultan Abdul Lama 'Ali Ahmad.

Pupuh $40 \quad$ Tumenggung

Wirautama diperintahkan Pangeran Abdul Kadir untuk membuat persiapan penyambutan pasukan mekah.
Pupuh $41 \quad$ Upacara penyambutan utusan Banten dan surat dari Sultan Mekah berlangsung dengan meriah. Diramaikan dengan bunyi senapan, meriam, dan gamelan serta disaksikan rakyat Banten.

Pupuh 42 Upacara pembacaan surat Sultan Mekah yang dibaca dengan gaya seperti khutbah Jumat oleh Pekih kerajaan Banten.

Pupuh 43 Pemberian hadiah dan gelar kepada para utusan banten yang berangkat ke Mekah. Demang Tisnajoyo mendapat gelar dan nama haji Jayasanta dan Mas Wangsaraja mendapat gelar Haji Wangsaraja.

Pupuh 44 Ibunda Sultan, Nyai Gedhe Wanogiri wafat dan dimakamkan di Kanari. Dceritakan tentang kebiasaan Sultan Banten jika melakukan perjalanan mengelilingi kerajaan.

Pupuh 45 Tentara Sultan Banten menerima sembah. Sultan selalu meminta nasihat pamannya, Pangeran Upapati untuk masalah kenegaraan.

Pupuh 46 Diceritakan Sultan Abdulmafakhir Mahmud Abdulkadir bermaksud memeriksa persawahan di Serang. Ia ingin membangun lumbung besar di alun-alun. Tugas membuat lumbung besar diserahkan kepada Ki Lumaju. Setelah selesai, Wirautama, Indapuspati dan Wangsadipa diperintahkan untuk memeriksa pekerjaannya. Indapuspati mencela pembuatan lumbung itu sehingga Lumaju marah dan pulang ke kampungnya. Sultan Banten marah dan menganggap 
Lumaju tidak bertanggung jawab. Oleh karena itu, ia memerintahkan Tubagus Arya Suta menangkapnya. Ia tidak berhasil menangkapnya, tetapi Sultan tidak marah. Bahkan Arya Suta diberi hadiah dan gelar Pangeran Arya Dikara.

Pupuh 47 Sultan Mataram meminta Sultan Cirebon Pangeran, Pakungwati menaklukkan Banten. Sultan Cirebon bersedia mengikuti perintah Sultan Mataran. Ia lupa pada pesan kakeknya, Panembahan Girilaya bahwa Cirebon tidak boleh ikut campur dalam urusan antara Mataram dan Banten karena Cirebon dan Banten bersaudara. Pangeran Pakungwati dan Singaranu pergi ke Banten. Mereka disambut dan dijamu dengan baik. Singgaranu meminta kepada Sultan Banen agar mengirim utusan ke Mataram.

Pupuh 48 Sultan Banten setuju. Ia mengirim $\mathrm{Ki}$ Jamisah dan Astranaya ke Mataram. Kedua utusan Banten berangkat bersama dengan Jawiring. Tiba di Mataram, mereka diperlakukan dengan baik, tetapi dengan cara yang menimbulkan kesan tidak aman. Para utusan banten pulang.

Pupuh 49 Ki Jamisah dan kawan-kawan ditanya kesan mereka berkunjung ke Mataram. Mereka menjawab bahwa Banten harus bersiapsiap berhadapan dengan Mataram.

Pupuh 50 Sultan Banten memerintahkan membuat gorab dan wangkang besar untuk persiapan perang melawan Mataram. Pembuatan kapal itu diberi sengkala: iku nunggang tata jurit (1751 SAKA).

Pupuh 51 Utusan Cirebon tiba di Banten. Mereka dijamu Pangeran Adipati.

Pupuh 52 Pangeran Martasari dari Cirebon gagal membujuk Sultan Banten untuk menghadap Sultan Mataram. Singaranu marah dan menuntut bukti kesetiaan Martasari (Cirebon) kepada Mataram. Ia diperintahkan menyerang Banten.

Pupuh 53 Pangeran Martasari bersama pasukannya menyerbu Banten, tetapi Banten berhasil mempertahankan diri, bahkan pasukan Cirebon dikalahkan. Rakyat Cirebon banyak yang mati. Sultan Banten marah karena kelakuan rakyatnya yang kejam kepada Cirebon. Peristiwa penyerbuan Cirebon ke Banten ini disebut Pacirebon atau Pagarage.

Pupuh 54 Pangeran Adipati, putra Sultan Abdulmaali dan cucu Sultan Abdulmafakhir Mahmud Abdulkadir ikut dalam acara sasapton (turnamen) yang berlangsung di Banten.

Pupuh 55 Setahun setelah peristiwa Pacirebon, Sultan Abulmafakhir Mahmud Abdulkadir wafat. Rakyat mengeramatkan dan menggelarinya Sultan Agung (I). Cucunya bernama Pangeran Adipati menjadi penggantinya dengan gelar Pangeran Ratu. Pangeran Madura sebagai Mangkubumi dan Enthol Kawista diangkat 
dan diberi nama sebagai Pakih Najamudin. Pangeran Adipati mengirim Santri Betot ke Mekah untuk mengabarkan kewafatan Sultan Abulmafakir Mahmud Abdulkadir dan pengangkatan dirinya. Pangeran Adipati kemudian juga meminta nama dan gelar kepada Sultan Mekah. Pangeran Adipati mempunyai seorang anak laki-laki bernama Pangeran Anom atau Pangeran Gusti. Sejak kecil ia diasuh pamannya yang bernama Pangeran Prabangsa.

Pupuh 56 Santri Betot pulang dari Mekah. Ia membawa surat dan tiga orang utusan Mekah ke Banten. Pangeran Adipati yang telah dikenal sebagai Sultan Agung (II) mendapat gelar dan nama baru, Sultan Abdul Fath Abdul Fattah.

Pupuh 57 Persiapan perang Banten melawan Belanda.

Pupuh 58 Sultan Abul Fath Abdul Fattah membagikan hadiah untuk memberi semangat kepada rakyatnya yang akan berperang melawan Belanda. Pasukan Banten tiba di Tanggeran.

Pupuh 59 Belanda mendengar pasukan Banten tiba. Mereka pun berangkat ke medan perang. Di perbatasan, kedua pasukan telah berhadapan, tetapi peperangan tidak juga dimulai. Keadaan seperti itu berlangsung 7 hari.

Pupuh 60 Pada hari kedelapan peperangan dimulai dan berlangsung selama tiga hari. Pasukan kedua belah pihak banyak yang gugur.

Pupuh 61 Prayakarti datang ke Surosowan untuk melaporkan keberhasilan pasukan daratnya menggempur Belanda. Sultan sangat gembira dan berjanji akan memberi hadiah kepada pasukannya.

Pupuh 62 Banten juga Berjaya dalam peperangan di laut.
Pupuh 63 Banten mengalami banyak kemenangan, di Karawang dan Tong Jawa (Untung Jawa).

Pupuh 64 Peperangan antara Belanda dan Banten berlangsung di darat dan di laut. Sultan Banten kemudian mengirimkan pasukan bantuan kepada Arya Mangunjaya di Tanggeran (Tanggerang). Terjadi perang dahsyat, Belanda kalah.

Pupuh 65 Setelah berperang selama 17 bulan dan Belanda mengalami banyak kekalahan, Panidya (Raad van Indie) meminta tolong kepada Jambi agar bersedia menjadi perantara perdamaian antara Belanda dan Banten. Perdamaian terjadi setelah peperangan berlangsung lebih dari satu tahun lamanya.

Pupuh 66 Sandisastra minta diceritakan mengenai peristiwa yang terjadi di Banten setelah pekerjaan (peristiwa jatuhnya jaketra ke tangan colonial belanda), tetapi sandimaya tidak mau karena sudah lelah. Cerita ditutup dengan peraturan-peraturan mengenai perang salib.

\section{Islamisasi di Tatar Sunda}

Kata islamisasi berasal dari bahasa Inggris, yakni Islamization yang berarti pengislaman, yaitu upaya seseorang agar orang lain menjadi penganut agama Islam. 
Dalam bahasa agama, proses islamisasi disebut dakwah yang berarti mengajak. Sebuah ajakan untuk mengubah anutan kearah kehidupan yang lebih baik dan sempurna. Dalam kata pengislaman maupun dakwah terkandung makna kata kerja (kegiatan atau proses) dinamis, dan aktif serta upaya menyampaikan ajaran agama Islam kepada orang lain secara individu maupun kelompok. (Heryana, 2015: 26)

Pelaku islamisasi seorang muslim dan sasarannya non muslim dan muslim. Sasaran non muslim menyangkut soal kuantitas dan sasaran muslim menyangkut soal kualitas.

$$
\text { Proses islamisasi di }
$$

Nusantara asendiri menurut teori historiografik klasik dilakukan melalui lima cara, yaitu ; (1) Islam dibawa langsung dari Arab, (2) Islam diperkenalkan oleh para guru dan penyiar 'profesional' yang khusus bertujuan menyebarkan Islam, (3) Islam pertamakali dianut oleh para penguasa, (4) penyebar Islam datang ke nusantara pada abad ke 12 dan 13 Masehi, dan (5) Islam disebarkan oleh kaum Sufi. (Azra, 1994:30-34) Adanya kelima teori yang memperlihatkan proses islamisasi di Nusantara ini menunjukkan betapa sulitnya untuk menjawab pertanyaan siapa dan kapan dimulainya penyebaran agama Islam di Nusantara.

$$
\text { Penelaahan teks Babad }
$$

Banten yang memfokuskan perhatian pada proses islamisasi di tatar Sunda, maka hanya membahas dari (1) tradisi keagamaan, (2) politik, dan (3) budaya (perkawinan dan pemberian gelar).

\subsection{Tradisi keagamaan}

Kehadiran Islam di tanah Sunda (Pajajaran) telah diakui sebelum jatuhnya Pajajaran pada tahun 1579 Masehi karena diserang Banten. Karakter kehidupan beragama masyarakat pada masa Pajajaran secara tidak langsung memudahkan Teori asal-usul bahasa

Dalam literatur islam klasik penerimaaan Islam sebagai agama masyarakat Pajajaran pada masa tersebut.(Heryana, 2015:28)

Sebagai contoh, cita-cita orang Pajajaran yang saleh adalah manggihkeun hyang tanpa balik dewa (bertemu dengan Hiyang bukan dewa) diartikan sebagai muksa yang artinya kembalinya sukma kepada dzat asalnya, kembali kepada Hyang karena Dialah "Si Tuhu Lawan Pretyaksa" ( yang hak dan yang wujud)(Heryana, 2015:30). Masyarakat Sunda yang hidup nomaden, ditandai dengan tinggal berpindah tempat di dekat ladang (huma) membuat mereka dengan mudah menjadikan batu alam yang bentuknya aneh untuk kemudian dijadikan titik pusat pemujaan. Mereka lebih mengutamakan isi daripada bentuk sehingga nilai kepraktisan sangat diutamakan.

Dalam keadaan seperti itu, sesungguhnya masyarakat tatar sunda sudah siap menerima ajaran Islam karena ciri pokok praktis, akrab dengan alam dan lebih menekankan kepada isi (niat). Hal ini dapat dilihat dari perilaku umat Islam yang dapat shalat dimana saja dalam waktu yang singkat.

Syiar agama diakukan seakrab mungkin, hal ini dapat dilihat dari nama masjid yang pertama didirikan oleh Walangsungsang di tepi pantai dinamai Jalagrahang (rumah air). 
Syarif Hidayat yang lahir di Mekah, dibesarkan di Mesir dan belajar bahasa Sunda dari ibunya menamai masjid Negara yang didirikannya Tajug Sang Ciptarasa. Bagi masyarakat Cirebon, kata Ciptarasa sangat menyentuh hati dan memberi kesan pemusatan fikiran untuk menjalin hubungan dengan yang gaib. ((Heryana, 2015: 33)

Istilah keagamaan lama seperti surga, naraka, sembah hyang, netepan, ngaji, pupujian, guru, dan istilah lainnya tetap digunakan hanya makna dan isinya disesuaikan dengan ajaran Islam.

Dari uraian diatas, dapat disimpulkan bahwa tidaklah tepat jika Pajajaran diasumsikan sebagai "Kerajaan Hindu" atau Jaman Pajajaran disebut sebagai "Jaman Hindu". Penamaan ini hanya akan menimbulkan salah tafsir atau salah faham karena di tatar Sunda sampai sekarang tidak ditemukan candicandi dengan maupun patungpatung para dewanya. Penyebaran agama Islam pada waktu itu terjadi karena para penyiarnya sendiri merupakan kaum atasan (elit). Jika bukan keturunan Rasulullah Muhammad, mereka berasal dari kaum keraton. Seandainya ada pedagang, maka mereka adalah saudagar kaya dan saudagar kaya dan sahabat penguasa pelabuhan.

Dengan demikian, maka dapat difahami mengapa penyiaran agama terjadi di sepanjang jalur perdagangan dunia waktu itu, karena para penyiar agama pergi ke tempat tujuannya menumpang kapal dagang dan singgah di berbagai pelabuhan terlebih dahulu

\subsection{Politik, Pendidikan dan Tindakan Tegas}

Proses penyebaran dan perluasan Islam lebih banyak dikisahkan melalui dua gerbang penyebaran, yaitu Cirebon dan Banten. Keduanya dikuasai seorang raja yang juga ulama, yaitu Sunan Gunung Djati yang bergelar Ratu Pandita.(Heryana, 2015:34)

Ekadjati (1983: 91) menyebutkan, Kesultanan Cirebon pada awal berdirinya berada dalam kekuasaan Kerajaan Hindu Sunda. Pada tahun 1479M. Syarif Hidayat diangkat Raja Sunda menjadi kepala daerah Cirebon dengan pangkat Tumenggung dan sebutan Susuhunan Jati. Beliau memutuskan untuk tidak mengirim bubekti (persembahan) kepada Raja Sunda. Artinya, ia melepaskan ikatan dengan Kerajaan Sunda dan menyatakan Cirebon berdiri sendiri. Sejak tahun 1470M, Cirebon cenderung menjadi pusat kegiatan penyebaran dan pendidikan Islam dengan Susuhunan Jati sebagai pemimpin dan gurunya. Berdasarkan hal ini, dapat difahami jika kemudian proses islamisasi di Banten tidak lepas dari Cirebon sebagai pusat penyebarannya dan Susuhunan Jati dan puteranya Pangeran Sabakingkin yang bergelar Pangeran Hasanudin (saat itu menjabat sebagai bupati ketika Banten telah ditundukkan Cirebon) pada tahun $1526 \mathrm{M}$. tahun $1552 \mathrm{M}$, Pangeran Hasanudin dikukuhkan sebagai Sultan Banten dan beliau terus menerus merintis jalan dan memimpin usaha pengislaman penduduk Banten sampai ke daerah pedalaman. (Heryana, 2015:35)

Teks BB menceritakan gambaran kedua orang tersebut sebagai berikut: seorang keramat yang bapaknya berasal dari Yamani dan ibunya dari Bani Israil. Dari Mandrasah ia datang ke Jawa, yaitu Pakungwati untuk mengislamkan 
daerah ini (14.22-14.25). Beliau mempunyai dua orang anak; seorang anak perempuan dan anak laki-laki yang bernama Molana Asanudin. Bersama Molana Hasanudin, ia berangkat ke arah barat, tiba di Banten Girang lalu terus ke selatan, ke Gunung Pulasari. Teks BB juga menyebutkan secara berurutan nama-nama para penguasa banten sebagai berikut: (1) Molana Hasanudin, (2) Molana Yusuf, (3) Molana Muhamad atau Kangjeng Ratu Banten Surasowan atau Prabu Seda ing Palembang, (4) Pangeran Abdullah Kadir dengan gelar Pangeran ratu, mendapat gelar dari Sultan Mekah menjadi Sultan Abulmafakhir Mahmud Abdulkadir atau Sultan Agung I, dan (5) Pangeran Adipati dengan gelar Pangeran Ratu atau Sultan Agung II atau Sultan Abul Fath Abdul Fattah. (Heryana, 2015: 35-36)

Babad Banten juga

menjelaskan bagaimana proses pendidikan yang dilakukan Sunan Gunung Jati dalam rangka mempersiapkan anaknya, Molana Hasanudin menjadi penyebar Islam. Berikut ini ringkasan teks BB yang menggambarkan kejadian tersebut.

Selanjutnya,

Molana

Hasanudin berkelana ke hutan-hutan dan di Gunung Pulasari (14.2514.26). ia menemukan pertapaan Beramil Khadali. Ayahnya mengajarkan Iman dan Islam serta ilmu alat lainnya seperti : fiqih, usul-fiqih, saraf, nahwu, manteq (logika), tafsir dan hadits (15.3-155); dan mempercayakan dia kepada dua jin, namanya Santri (yang tak dapat dilihat orang lain), setelah itu ia kembali ke Pakungwati (15.615.8). Setelah tujuh tahun hidup terus menerus bertapa dari satu tempat ke tempat lainnya, ia kemudian mendapat kunjungan ayahnya yang mengajak melakukan ibadah haji (15.13-15.17). (Heryana, 2015:36)

Kutipan teks BB diatas mempelihatkan bagaimana Sunan Gunung Jati mendidik anaknya dengan serius sehingga kesiapan sang anak untuk menjadi penyiar agama Islam dapat terwujud karena sebelumnya beliau membekali ilmu agama Islam dengan baik, tidak membeda-bedakan status sehingga lahirlah kesetiaan dan penghormatan.

Tradisi

memberikan pendidikan keagamaan sejak dini kepada para putra raja ini terus berlanjut. Maulana Yusuf yang berputera Ratu Khotijah, Ratu Wanangon, dan Maolana Muhammad (20.4) mempercayakan pendidikan puteranya Maolana Muhammad, untuk dididik oleh Kyai Dukuh atau Pangeran Kasunyatan. Ia diajari ilmu agama seperti Hadits, al Qur'an, tafsir, fiqih semua kitab unggul. (Mahmudah. Zahrotul dan Tri Kurnia Dewi, 2011)

Ketegasan dalam bertindak ditafsirkan sebagai bentuk kekerasan pemaksaan kehendak. Dalam hal ini, unsur kekerasan hubungannya dengan aktualisasi diri dan unjuk kekuasaan tidak dapat dihindari dalam rangka penegakan hukum (syariat Islam) menjadi wajib untuk dilakukan. Tercatat, ada enam kali peristiwa peperangan yang terjadi, yakni: (1) penaklukan Banten Girang, (2) penyerangan Pakwan, (3) perebutan kekuasaan oleh Pangeran Jepara, (4) ekspansi Palembang, (5) pemberontakan Pailir, dan (6) peristiwa Pacirebonan atau Pagarage. (Heryana, 2015:38) 
Berdasarkan hasil telaah teks BB yang membahas masalah ini, maka penulis dapat menyimpulkan bahwa peperangan yang terjadi semata-mata dilandasi oleh motif untuk melaksanakan syariat Islam yang pelaksanaannya pun sesuai tuntunan agama. Dengan demikian, asumsi bahwa Islam disebarkan melalui jalan kekerasan sama sekali tidak benar.

\subsection{Budaya (perkawinan dan pemberian gelar)}

Kajian teks BB menunjukkan bahwa tampaknya, perkawinan menjadi salahsatu upaya yang dilakukan untuk melanggengkan kekuasaan. Perkawinan menjadi sebuah upaya yang bertujuan untuk menggabungkan hubungan dua keluarga yang berbeda menjadi satu kesatuan yang kuat. Adanya perkawinan ini baik secara langsung atau tidak, mampu mengikat setiap orang yang memiliki pertalian darah.

Berikut ini petikan teks BB yang menggambarkan peristiwa perkawinan Molana Hasanudin. Di Cirebon, para wali duduk bersama. Pangeran Kalijaga mengusulkan untuk melamar puteri Suntan Demak bagi Hasanudin yang berumur 27 tahun. Molana Bagdad kemudian mengirim Pangeran Panjunan ke Demak. Lamaran diterima dan sultan sendiri datang ke Cirebon untuk menjemputnya. Setelah tiba di Demak (ketika menanti waktu pernikahan yang tepat), tiba-tiba terjadi penyerbuan Raja Majapahit. Raja Majapahit berhasil di kalahkan dalam peperangan tersebut dan gugur, tetapi seorang wali yakni Molana Rahmat meninggal. Setelah itu, pernikahan dilakukan dan kedua mempelai tinggal selama empat bulan di Demak. Para pengantarnya kemudian pergi ke Cirebon (16.116.39). Peristiwa pernikahan lainnya yang ditulis dalam teks BB nomor 30.1-30.15 menggambarkan pernikahan putera Pangeran Jaketra, yaitu Pangeran Pekik dengan Ratu Martakusuma yang dihadiri oleh berbagai kalangan dan bangsa Cina, Keling, Inggris dan Belanda. ((Heryana, 2015: 47-48)

Mekkah, dalam teks BB menjadi puncak penyempurnaan ilmu-ilmu para santri. Sebagai contoh, Molana Hasanudin dibawa ayahnya ke Mekah setelah dia berhasil meguasai ilmu-ilmu alat untuk memahami al Qur'an dan hadits, kemudian beliau belajar ilmu agama disana. Azra (1994:59) menyebutkan,Ilmu yang diperoleh di Haramayn (Mekkah) dipandang lebih tinggi nilainya daripada ilmu yang diperoleh di pusat-pusat keilmuan lainnya.

Tradisi pemberian nama setelah melaksanakan ibadah haji telah berlangsung setidaknya pada abad ke 16 M dan menjadi daya tarik tersendiri. Berikut ini petikan naskah Teks BB menggambarkan bagaimana penganugrahan nama itu berlangsung.

Bermula pangeran Abdullah Kadir ingin mengirim utusan ke Mekah. Ia membentuk tim yang dipimpin Lebe Panji dan Tisnajaya serta Wangsaraja. Pangeran memberinya tiga kitab, yaitu Markum, Muntahi dan Wujudiah untuk ditanyakan kepada Sultan Mekah (34.13). Selanjutnya, ia meminta ahli fiqih mengajar di Banten dan membawa hadiahhadiah. (35.1-35.9). Rombongan tiba di Jedah dan menghadap Sultan Sarif Jahed (37.1). Sultan berunding dengan para wajir atas permintaan 
Pangeran Banten. Sebagai balasan hadiah, Sultan Mekah mengirimkan: (1) sehelai bendera yang berasal dari Nabi Ibrahim; setiap bulan mulud bendera itu harus dibawa berkeliling dengan upacara iring-iringan (helaran); (2) sepotong kain tirai penutup makam Nabi Muhamad SAW; (3) sepotong kiswah penutup kabah. Arti ketiga kitab yang ditanyakan Pangeran telah ditulis sultan. Selanjutnya, Sultan memberi gelar kepada Sultan Banten dengan sebutan Sultan bumufakhirMahmud Kabir dan kepada puteranya dengan sebutan Sultan Bumanggali Ahmad (37.25).Sultan Mekah ingin memberikan gelar kepada raja-raja Mataram dan Makasar, tetapi pemberian gelar tersebut harus melalui raja Banten. Ketiga sultan harus bekerjasama menentang kaum kafir. Hanya permohonan mengirimkan guru ahli fikih ke Banten yang tidak bisa dikabulkan (37.26-37.46). (Heryana, 2015: 50-51)

\section{Simpulan}

Kajian mengenai sejarah islamisasi tatar Sunda menarik untuk terus digali dari sumber aslinya langsung yaitu naskah kuno yang merupakan warisan kekayaan intelektual masa lalu. Sudah selayaknya kita mau membuka diri terhadap informasi yang berasal dari kearifan local masyarakat tatar Sunda. Museum Sri Baduga menyimpan banyak manuskrif kuno yang membahas islamisasi di tatar sunda dan sampai saat ini masih sedikit para akademisi serta peneliti yang mempergunakan hasil transliterasi yang dilakukan para ahli filologi.

Dalam kaitannya dengan proses islamisasi yang termuat dari teks naskah Babad Banten (BB) diperoleh kesimpulan sebagai berikut : Pertama ; islamisasi tidah hanya dilakukan melalui jalur politik dengan mengatasnamakan kekuasaan atau kewenangan sultan semata. Kedua, islamisasi tidak pernah dilakukan melalui jalur kekerasan atau perang tanpa alasan yang jelas. Penyerangan atau ekspansi kekuasaan lebih disebabkan oleh factor politik dengan motif perebutan kekuasaan. Ketiga, islamisasi yang memberikan dampak besar melalui pendekatan budaya atau tradisi karena semua lapisan masyarakat terlibat langsung secara emosi. Keempat, proses islamisasi sendiri tidak akan terjadi tanpa adanya kesiapan yang kuat dari para penyiar agama itu sendiri. Kesungguhan sultan mendidik putranya dalam ilmu agama merupakan bukti betapa hal ini menjadi satu keharusan untuk menyiapkan diri penerus syiar Islam di masa yang akan datang.

\section{Daftar Pustaka}

Azra.Azyumardi.1994. Jaringan Ulama Timur Tengah dan Kepulauan Nusantara abad XVII dan XVIII. Bandung. Mizan.

Ekadjati, Edi.S (ed). 1983. Masyarakat Sunda dan Kebudayaannya. Jakarta. Girimukti Pasaka

Djajadiningrat.Hosein.1983.Tinjauan Kritis tentang Sejarah

Banten.Terj.Jakarta.Djambatan Heryana.Agus. 2015.Bentuk-bentuk Islamisasi Pada Naskah Babad Banten (07.74) Koleksi Museum Sribaduga. Makalah Prosiding Penelusuran Jejak Islamisasi Melalui Naskah Kuno 
Kuntowijoyo.2003.Metodologi

Sejarah

Edisi

Kedua.2003. Yogyakarta.

TiaraWacana Yogya.

Kurnia.Anwar

dan

Suryana.Moh.2006.Kronik

Sejarah.Jakarta. Yudhistira

Mahmudah. Zahrotul dan Tri Kurnia

Dewi.2011. Babad Banten

(07.74): Transliterasi Teks dan

Terjemahan.

Dinas

Kebudayaan dan Pariwisata

Jawa Barat Balai Pengelolaan

Museum Negeri Sribaduga

Pudjiastuti.Titi.2007.

Perang,Dagang Persahabatan:

Surat-surat Sultan Banten.

Jakarta.Yayasan Obor

Indonesia 